\title{
Enterprise architecture adoption issues and challenges: a systematic literature review
}

\author{
Nor Azizah Ahmad ${ }^{1}$, Sulfeeza Mohd. Drus ${ }^{2}$, Nur Azaliah Abu Bakar ${ }^{3}$ \\ ${ }^{1,2}$ Universiti Tenaga Nasional, Malaysia \\ ${ }^{3}$ Teknologi Malaysia, Malaysia
}

\begin{tabular}{l}
\hline \hline Article Info \\
\hline Article history: \\
Received Dec 15, 2018 \\
Revised Feb 17, 2019 \\
Accepted Mar 2, 2019 \\
\hline
\end{tabular}

\section{Keywords:}

Enterprise Architecture

Adoption

EA Issues

EA Challenges

Systematic Literature Review

\begin{abstract}
This article on Systematic Literature Review (SLR) provides the issues and challenges faced by organizations when adopting EA. Firstly, a review of literature that discusses the problems and challenges was undertaken. Methods and theories adopted were reviewed to identify the existing approach and perspective on resulting factors that influenced EA adoption. Based on the inclusion and exclusion criteria defined in the review process, 16 articles were selected. A total of 19 challenges and problems were identified such as EA misconceptions, overlapping organizational rules, unclear leadership as well as lack of business and IT alignment. A sum of 15 factors from multidimensional contexts that influenced the EA adoption in the organization were also discussed, such as top management support, governance, communication as well as EA knowledge and skill. This SLR also reflected that there were relatively little empirical studies conducted on EA adoption studies. The existing studies tend to apply single and multiple theories from the organization and management domains in one study. By understanding such issues and challenges, risks can be reduced and avoided when introducing EA to organizations, and subsequently ease the deployment process. Thus, this article may shed light on understanding the organizational-related factors and the underlying relationships of EA adoption. As a result, an effective adoption of EA can be facilitated in the organizations.
\end{abstract}

Copyright $\odot 2019$ Institute of Advanced Engineering and Science. All rights reserved.

\section{Corresponding Author:}

Nor Azizah Ahmad,

Department of Informatics,

College of Computing and Informatics,

Universiti Tenaga Nasional Putrajaya, Malaysia.

Email: norazizah.ahmad@gmail.com

\section{INTRODUCTION}

Enterprise Architecture (EA) effectively integrates different domains in business, data, application, and information in organizations. Through this, the business and technical community can have a mutually understandable language in their communication to achieve the organization's goal, for example, citizencentric services. In the field of EA, various definitions of EA are found. Zachman [1], the first scholar in EA defined the term as a perspective that consists of artefacts, which is a set of descriptive representations such as models that are relevant to be produced and fulfilled according to the stakeholders or top management's requirements. The quality of the models is important because these models captured the change and are maintained over the period of useful life. In other thoughts, EA is a coherent whole of principles, methods, and models that are used in the design and realization of an enterprise's organizational structure, business processes, information systems, and IT [2-3]. This definition related to EA components which include Organizational Architecture, Business Architecture, Information Architecture, Application Architecture, and Technological Architecture [4]. These components are integrated to provide a long-term view of the 
organization [5]. Besides, Behrouz and Fathollah [6] defined EA as the process of translating and converting strategic requirements to processes, data, and technology by providing the organization with a big picture in detail. EA is also able to handle change management as it acts as a management tool between business and IT $[5,7]$. There is no doubt that EA plays an essential role in facilitating the evolution to higher level capabilities at the organizational level $[8,9]$.

When introducing Information System (IS) innovation to the organization, the adoption appears as the main challenge. This phenomenon is widespread and appears to EA as well [10]. Although the maturity of the EA related standards and practices have improved over the years, the process of adopting EA is still slow in the organization and as a result; contributes to the low adoption rate of EA and in some cases, not widely accepted by organizations [11-13]. The Computer, Economic Report stated that EA is still not widely embraced, as in 2017 only $53 \%$ of IT organizations practice EA compared to the previous year with 59\% [12]. This may be influenced by many constraints of technology, organization, environment or external pressures such as politics and sponsors [14-22]. However, the EA field does not have a clear and strategic dimension, manily because of the number segmented approaches and solution in the previous studies. As a consequence, it becomes difficult and confusing to choose the adoption model for organization that fits one's need when adopting EA in the organization [23]. Furthermore, the researchers may find it challenging to find factors and solution of EA adoption in organization [24].

Previous studies tackled the issues from a single perspective in regards to EA adoption studies, for example, in the context of organizational pressure such as government regulations, mandate or politics [17, $23,25-28$ ], as well as in the context of the organizational environment [29]. The organizational issue for example, is the misperception that EA is a technical task and not a business task. Hence, this leads to a breakdown in communication between business and technical needs [16, 30-32]. EA, therefore, is often left to IT people to manage instead of emphasising on a collaborative effort from both business and IT. Meanwhile, other scholars investigated EA adoption from the perspectives of business and technology [31] or technology alone [33]. Along with this line, one example include Syynimaa [27] that had proposed a solution for the absence of understanding EA concepts. The research efforts have not dealt with wide-ranging perspective to address issues and challenges related to EA adoption [26]. According to Cram, et al. [34], the technological context includes the internal and external technologies that are relevant to the firm. Technologies may include both types of equipment as well as processes [15]. Meanwhile, the organizational context refers to the characteristics and resources of the firm, including the firm's size, the degree of centralization, the degree of formalization, managerial structure, human resources, amount of slack resources, and linkages among employees $[15,35]$. Then, the environmental context includes the size and composition of the industry, the firm's competitors, and the macroeconomic context, [15]. Finally, the organizational pressure focuses on the pressure of normative, coercive and mimetic [19]. Normative pressure relates to norms or standard, certification, and accreditation, whereby coercive pressure refers to formal pressure such as mandate, and lastly mimetic pressure refers to imitation, following others or taking it for granted.

Considering this evidence, there is a lack of research covering the all-inclusive perspectives in the EA adoption study. This is also a strong scientific motivation for this study. By understanding such issues and challenges, it can help in reducing and avoiding risk when introducing EA to organizations, and subsequently ease the deployment process. Thus, this motivates more research and practical guidance for organization to implement EA. Therefore, this paper conducts an SLR to identify the issues and challenges, influence factors, and research methods in existing EA adoption studies. The goals of this paper are to to identify and review the current evidence relating to EA adoption based on the criteria and scope that will be presented in the section 2 . The results of this paper identify existing issues and challengis hindering the EA adoption, characterize factors influencing EA adoption, and discuss the research approaches in the previous studies of EA adoption. This research will be expanded to investigate the EA adoption from these proposed contexts namely, Technological, Organizational, Environmental and Organizational Pressure (TOEP). This knowledge will generate fresh insights into developing a new EA adoption model in Technological, Organizational, Environmental and Organizational Pressure (TOEP) context. It is expected that, with this systematic review, could extend the Enterprise Architecture Body of Knowledge (EABOD) by helping the researchers and practitioners to acquire a lot of data regarding the EA field, and create higher implementation or analysis selections. The structure of this paper is organized as follows; Section 2 presents the Methodology of this study; Section 3 describes the Results and Discussions of the review; Section 4 presents the Research Gap; and finally, the Conclusion and Future Works are shown in Section 4.

\section{RESEARCH METHOD}

This paper adopts SLR guidelines of Barbara and Stuart [33] to identify and review the current evidence relating to the criteria and scope towards EA adoption. An SLR is a primary study that encompasses 
secondary study and individual studies. The SLR guidelines consist of three main phases. The first phase is planning the review that consists of three mandatory stages; the identification of the need for a review; specifying the research question(s) and developing a review protocol. The second phase is conducting the review which involves identification of research, selection of primary studies, study of quality assessment, data extraction and monitoring, and data synthesis. In the final phase is reporting the review that covers stages of specifying dissemination mechanisms and formatting of the main report.

\subsection{Planning the Review}

This study follows the criteria by Barbara and Stuart [33] to design the SLR questions. Table 1 shows the criteria and scope of research questions structure. The following research questions are thus formulated and grounded in the research structure as shown in Table 1.

1. What are the issues and challenges in EA adoption by organizations?

2. What are factors that influence EA adoption in organizations?

3. What are the research methods used in EA adoption studies?

In this study, published articles were reviewed from six online scientific databases that have indexed "Enterprise Architecture" or "Information Technology Architecture" and provided full-text access to relevant publications. The online databases comprised of the ACM Digital Library, Scopus, SpringerLink, ScienceDirect, Emerald, Wiley and Google Scholar.

Table 1. Criteria and Scope of Research Questions Structure

\begin{tabular}{cl}
\hline Criteria & Scope \\
\hline Population & EA adoption in organizations \\
Intervention & Issues and challenges, influence factors, and research method in EA adoption studies \\
Comparison & Issues, challenges, influence factors and research method \\
Outcomes & List of issues, challenges, influence factors, and research methods in EA adoption study \\
Context & Review of any studies on EA adoption \\
\hline
\end{tabular}

\subsection{Conducting the Review}

Search terms comprised of the following combinations; 'enterprise architecture', 'adoption', 'challenge', 'issues', 'research method', 'theory', influence factor'. The search string is then assembled using Boolean connectors "AND" and "OR" to allow synonyms and word class variations of each keyword. The search string was fulfilled in the online database to titles, abstracts, and metadata, assuming that these offer a short outline of the work. The sources of papers are selected based on inclusion criteria defined above from journals, conferences, and theses. The criteria comprised of articles in English from journal articles, conference proceedings, technical reports, theses, and books as well as studies that fit the aforementioned research questions. Articles that are not written in English and mismatched the inclusion criteria were excluded.

\section{RESULTS AND DISCUSSIONS}

This section will discuss the results and discussions of the SLR. Initially, a total of 1,674 studies were retrieved from the aforementioned databases using the search strategy. After exhaustive elimination over the titles and abstracts, only 51 studies were found to be potentially relevant. Then, full-text articles were used when abstracts were not adequate in identifying the relevance of a particular paper. The remaining 51 articles were filtered by looking at the introduction, headings, and conclusions. Finally, after a thorough evaluation of relevant articles and exclusion of duplicates, only 16 studies were recognized for the synthesis of evidence. Having defined the literature selection process, the next part is to report the results and analysis for SLR questions. Figure 1 shows the process flow of SLR.

\subsection{Result RQ1: What are the Issues and Challenges in EA Adoption by Organizations?}

The table presents the identification of issues and challenges faced by organizations with regard to EA adoption from literature. These identified issues and challenges are grouped into four contexts namely Technological, Organizational, Environmental and Organizational Pressure (TOEP) as proposed in Section 1. The issues and challenges are presented in Table 2. Previous scholars tackled the issues from a single perspective, for example, in the context of organizational pressure such as government regulations, mandate or politics [17, 25-28], or in the context of the organizational environment [29].

Previous scholars tackled the issues from a single perspective, for example, in the context of organizational pressure such as government regulations, mandate or politics [16], [22]-[25], or in the context 
of the organizational environment [26]. Meanwhile, other scholars investigated EA adoption from both perspectives of business and technology [28] or technology alone [30]. On the other hand, organizational pressures are critical when examining organizational change. What stands out in Table 2 is that there are numbers of issues centred on the non-technical aspects form as organizational and environmental contexts. This includes the misconception of EA, lack of business-IT alignment, lack of management support, organizational procedure, and lack of EA use.

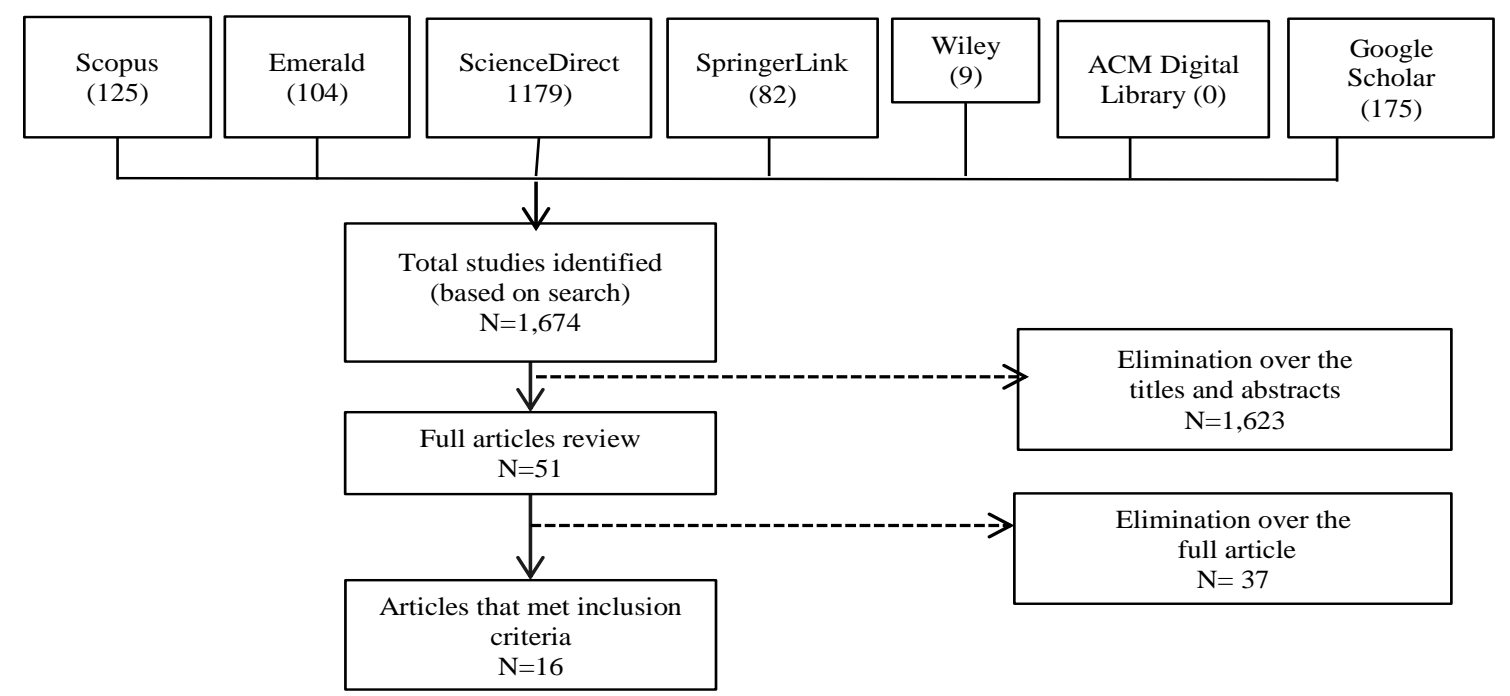

Figure 1. SLR Process Flow

Table 2. Issues and Challenges Identified from the Literature Review.

\begin{tabular}{lcll}
\hline Context & Issues and challenges & Source $(\mathrm{s})$ \\
\hline Organisation & 1. & Poor Governance & {$[26],[28],[34],[3]$} \\
& 2. & Insufficient resources & {$[26],[28][$ [3] } \\
& 3. & Lack of business-IT alignment & {$[26],[35],[30],[28],[3]$} \\
& 4. & Misconception of EA & {$[26],[34],[3],[9],[29],[24]$} \\
& 5. & Lack of EA knowledge and skill & {$[28],[24]$} \\
& 6. & Lack of management support & {$[26],[34],[24],[23]$} \\
& 7. & Unclear leadership & {$[26],[34],[23],[24]$} \\
& 8. & Huge programme scope & {$[26]$} \\
Environment & 9. & Communication failures & {$[26],[29],[28]$} \\
& 10. & Lack of awareness and readiness & {$[34],[23],[28]$} \\
& 11. & Lack of EA use & {$[26],[34],[15]$} \\
Technology & 12. & Organizational procedure & {$[26],[34],[35],[36],[23]$} \\
& 13. & Competition with other best practices & {$[26]$} \\
Organizational & 14. & Rigid and incompatible IT systems & {$[30],[28],[26]$} \\
pressures & 15. & Difficulties in modelling & {$[26]$} \\
& 16. & Lack of perceived value & {$[26],[24],[34]$} \\
& 17. & Legislation and mandate or coercive & {$[24],[34],[23]$} \\
& 18. & Lack of motivational factors & {$[26]$} \\
& 19. & Mimetic & {$[23],[15]$} \\
\hline
\end{tabular}

Meanwhile, other scholars investigated EA adoption from both perspectives of business and technology [31] or technology alone [33]. On the other hand, organizational pressures are critical when examining organizational change. What stands out in Table 2 is that there are numbers of issues centred on the non-technical aspects form as organizational and environmental contexts. This includes the misconception of EA, lack of business-IT alignment, lack of management support, organizational procedure, and lack of EA use.

Further analysis shows that the misconception of EA is the critical problem that had been addressed by previous researchers, followed by organizational rule, lack of business and IT alignment, unclear leadership, lack of management support and governance. The organizational issue for example, the misperception that EA is a technical task and not a business task. Hence, this leads to a breakdown in communication between business and technical needs which results in the concept of EA being 
misunderstood by top managers [15], [27-29]. EA, therefore, is often left to IT people and thus leads to poor EA investment in organizations [37]. A specific study by the Norwegian Association of Higher Education Institutions revealed that fragmented applications developed due to organizations not understanding business needs and thereby cause a communication breakdown [30]. Moreover, in Finland for instance, although the Act on Information Management Governance in Public Administration 2011 has mandated the public sector organizations to start adopting EA by 2014, the EA adoption level and maturity is still low [24], [26]. Meanwhile, the least issues faced by organizations are competing with other best practices, huge project scope and lack of motivational factor. Together these results provide important insights that most issues are rooted in the organizational and environmental contexts. Undoubtedly, organizational pressures such as mandate and regulatory requirements also encourage organizations to make decisions.

\subsection{Result RQ2: What are Factors that Influence EA Adoption in Organizations?}

The result from literature contributes to the identification of 15 factors that influence EA adoption by organizations as presented inTable 3. These identified factors are also grouped into four contexts as suggested in Section 1 namely Technological, Organizational, Environmental and Organizational Pressure (TOEP). It is observed that there are common factors identified from different studies for instance; governance, communication, top management support, resources and organizational readiness. Indisputably, technological factors like technology complexity, technology readiness, and vendor support also play an important role as well as environmental aspects when adopting EA in the organizations. According to Tom Dunlap, research director for Computer Economics, an IT research firm based in Irvine California, EA is a time-sensitive process that requires an agreement between business and IT personnel for gaining mutual understanding and decision [11]. Therefore, organizations are not likely to adopt and use EA unless the relevant personnel are ready. These personnel include users at different levels who execute different business function such as employees who handle human resources management, strategic development, IT specialists who provide technical support, and managers who make decisions based on the information obtained [5]. These important personnel are generally referred to as organizational users [38].

Detailed inspection of the findings shows that very few research had taken into consideration the element of pressures like mimetic, coercive and normative. A study shows that the EA adoption level and maturity in the Finnish Higher Education is still low [24], [26] despite an Act has been mandated to public organizations. This can be inferred that external pressures like mandates, government regulations or policies alone do not guarantee that organizations could quickly adopt EA as innovation and without difficulty [23], [39]. Other researchers claimed that the success rate of EA is low; hence become infamous due to problems related to costs, time, results, requirement mismatch, and other non-technical problems [34]. In addition, in order for organizations to be dynamic and efficient, they need to respond to the challenges in terms of agility in processes, landscape, business rules and governance [13], [22-23]. Even the policies and programs do not always guarantee new initiatives will be adapted successfully to the organization [39]. However, these influential factors have a significant positive toward EA adoption. It is evident that the literature in this area of EA adoption still lacks in studies that relate to multidimensional factors such as technological, organizational, environmental, and organizational pressure in EA adoption.

\subsection{Result RQ3: What are the Research Methods Used in EA Adoption Studies?}

There are various research approaches in the previous studies of EA adoption. It can be categorized into three research approaches which are qualitative, quantitative and mixed-method. What is striking about the figures is the number of studies employed interview and case study is $35 \%$ individually. The figure contributed $70 \%$ of the total studies. In contrast, the figure for a quantitative approach that applied survey method is $18 \%$. On the other hand, only $12 \%$ of studies had employed a mix-method approach in EA adoption. Figure 2 describes the details of the existing research methods applied.

The major findings from previous studies have been tested with a qualitative approach. This approach had only focused for qualifying the phenomenon of interest through perceptions and values, and capturing the complexity of the phenomenon. As there is a scarcely empirical study from the survey as shown in Figure 2, the research would have been more pertinent if a broader range of EA adoption had been explained in the explanatory research. A better study would be to survey a larger population, randomly selected samples of society with the focus on determinants of EA adoption. As such, existing attempts are made in an exploratory research approach or descriptive in nature, and although there is still the absence of studies that apply prevalent models; this may be remaining to the novelty of the topic. This opens a new avenue for empirical study and increases the generalizability of EA adoption research. 


\begin{tabular}{|c|c|c|c|c|c|c|c|c|c|c|c|c|c|c|c|c|c|}
\hline 苞 & 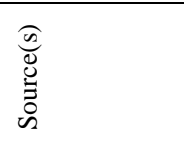 & $\stackrel{\sigma}{=}$ & $\infty$ & 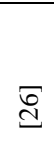 & $\bar{m}$ & 导 & $\bar{\Xi}$ & $\underset{\mathrm{I}}{\mathrm{J}}$ & $\overline{\bar{n}}$ & $\bar{n}$ & $\stackrel{\bar{\infty}}{\beth}$ & 6 & $\widetilde{\Xi}$ & 茎 & $\stackrel{\bar{g}}{ \pm}$ & $\overline{\widetilde{U}}$ & Total \\
\hline \multirow{12}{*}{ 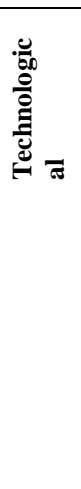 } & Technology & & & & & $\sqrt{ }$ & & & & $\sqrt{ }$ & & & $\sqrt{ }$ & $\sqrt{ }$ & & & 4 \\
\hline & Readiness & & & & & & & & & & & & & & & & \\
\hline & Vendor & & & & & $\sqrt{ }$ & & & & & $\sqrt{ }$ & & & & & & 3 \\
\hline & Support & & & & & & & & & & & & & & & & \\
\hline & Technology & & & & & & & & & & & $\sqrt{ }$ & $\sqrt{ }$ & & & & 2 \\
\hline & $\begin{array}{l}\text { Complexity } \\
\text { Top }\end{array}$ & & $\sqrt{ }$ & & & $\sqrt{ }$ & $\sqrt{ }$ & $\sqrt{ }$ & $\sqrt{ }$ & $\sqrt{ }$ & & & & & & & 6 \\
\hline & Management & & & & & & & & & & & & & & & & \\
\hline & Support & & & & & & & & & & & & & & & & \\
\hline & Relative & & & & $\sqrt{ }$ & & $\sqrt{ }$ & & & & & & & & $\sqrt{ }$ & & 3 \\
\hline & Advantage & & & & & & & & & & & & & & & & \\
\hline & $\begin{array}{l}\text { Organizational } \\
\text { Readiness }\end{array}$ & & & $\sqrt{ }$ & & & & & & $\sqrt{ }$ & & & $\sqrt{ }$ & & & & 3 \\
\hline & $\begin{array}{l}\text { Organizational } \\
\text { Culture }\end{array}$ & & & $\sqrt{ }$ & & & & & & & & & & & & & 1 \\
\hline \multirow{3}{*}{ 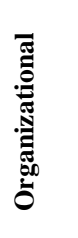 } & $\begin{array}{l}\text { Communicatio } \\
\mathrm{n}\end{array}$ & & & & & & & & & & $\sqrt{ }$ & $\sqrt{ }$ & $\sqrt{ }$ & & & & 3 \\
\hline & $\begin{array}{l}\text { EA } \\
\text { Knowledge } \\
\text { and Skill }\end{array}$ & & $\sqrt{ }$ & & & & $\sqrt{ }$ & $\sqrt{ }$ & & & & & $\sqrt{ }$ & $\sqrt{ }$ & & & 5 \\
\hline & $\begin{array}{l}\text { Financial } \\
\text { Commitment }\end{array}$ & & & & & $\sqrt{ }$ & & & & & & & $\sqrt{ }$ & & & & 2 \\
\hline \multirow[b]{2}{*}{ 佘 } & Governance & & & & & $\sqrt{ }$ & & & $\sqrt{ }$ & & $\sqrt{ }$ & & $\sqrt{ }$ & $\sqrt{ }$ & $\sqrt{ }$ & & 6 \\
\hline & $\begin{array}{l}\text { Competitive } \\
\text { Pressure }\end{array}$ & & & & & $\sqrt{ }$ & & & & & & & & & & & 1 \\
\hline \multirow{3}{*}{ 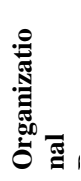 } & Mimetic & $\sqrt{ }$ & & & & & & & & & & & & & & $\sqrt{ }$ & 2 \\
\hline & Coercive & $\sqrt{ }$ & & & & & & & & & & & & & & $\sqrt{ }$ & 2 \\
\hline & Normative & $\sqrt{ }$ & & & & & & $\sqrt{ }$ & & & & & & & & $\sqrt{ }$ & 3 \\
\hline \multicolumn{2}{|c|}{ TOTAL } & 3 & 2 & 2 & 1 & 6 & 3 & 3 & 2 & 3 & 3 & 2 & 7 & 3 & 2 & 3 & 45 \\
\hline
\end{tabular}

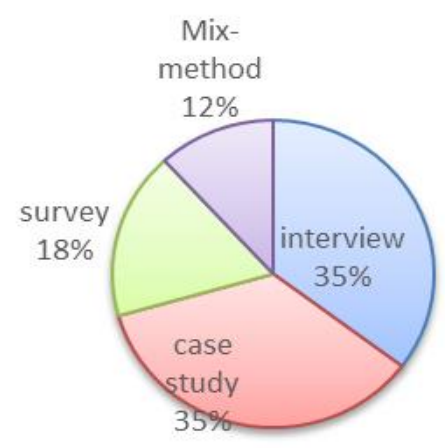

Figure 2. Result of research methods used in EA adoption studies

It is also found that the major studies conducted were centred in developed countries such as USA, Finland, and Belgium with a total of 8 out of 16 studies identified. On the other hand, the EA adoption studies were hardly undertaken or given attention by developing countries such as Malaysia, Vietnam and South Africa. Only one study on this topic was conducted in Namibia, UAE, and Iran. This scenario indicated that there is a lack of EA adoption studies despite the increasing attention from these developing countries. Since most EA adoption studies were mainly undertaken in European countries, it is hardly applicable in developing countries due to different governance structures, resources, IT awareness and IT literacy [34].

It is also found that the major studies conducted were centred in developed countries such as USA, Finland, and Belgium with a total of 8 out of 16 studies identified. On the other hand, the EA adoption studies were hardly undertaken or given attention by developing countries such as Malaysia, Vietnam and 
South Africa. Only one study on this topic was conducted in Namibia, UAE, and Iran. This scenario as presented in Figure 3 indicates that there is a lack of EA adoption studies despite the increasing attention from these developing countries. Since most EA adoption studies were mainly undertaken in European countries, it is hardly applicable in developing countries due to different governance structures, resources, IT awareness and IT literacy [37]. An Analysis of Theories used in EA Adoption Studies as shown in Table 4.

Table 4. An Analysis of Theories used in EA Adoption Studies

\begin{tabular}{lc}
\hline Theory/Model/Framework & No. of studies \\
\hline Deductive Qualitative Analysis (DQA) & 1 \\
The Grounded Theory & 1 \\
Activity Theory & 1 \\
Actor-Network Theory & 1 \\
Structuration Theory & 1 \\
Archer's Morphogenetic Theory & 1 \\
Institutional Theory & 2 \\
TOE & 1 \\
DOI & 1 \\
Management Theory & 1 \\
Project Portfolio Management (PPM) & 1 \\
KAOS Metamodel & 1 \\
COBIT 5 & 1 \\
Maturity Models & 1 \\
TAM & 1 \\
Method Evaluation Model & 1 \\
UTAUT & 1 \\
Critical Success Factor & 2 \\
Axiomatic Design & 1 \\
Total & 21 \\
\hline
\end{tabular}

\section{RESEARCH GAP}

After reviewing the above stated existing literature, concerned segmented dimension of EA adoption, the paper figures multidimensional issues and factors needed to be focused to strengthen the existing EA adoption approaches.

a. Segmented issues and factors: there are paucity in addressing issues and identifying factors from multidimensional.

b. Less study in developing countries: most established studies focussed in developed countries such as Norway, US and Belgium. It is hardly applicable in developing countries due to different governance structures, resources, IT awareness and IT literacy.

c. Generalizability: existing attempts are made in a qualitative approach through experts' interview and focus group discussion. This approach is expert dependency and may raise issue in term of generalizability. On the other hand, there is still the absence of studies that apply prevalent models or theories, huge population, and generalizing the perception of the research. This opens a new avenue for empirical study and increases the generalizability of EA adoption research.

d. Insufficient benchmarking: there are an insufficient effective proposed solution found in the previous studies towards EA adoption in organization.

\section{CONCLUSION}

Overall, these results indicate that EA adoption studies from the integrated context of technological, organizational, environmental and organizational pressure are still absent. It is apparent that previous scholars tackled the issues from a fragmented perspective, for example, only in the context of organizational pressure such as government regulations, mandate or politics, and organizational environment such as lack of top management support. Furthermore, literature in this area of EA adoption is still low especially for studies that relate to multidimensional factors. It is also found out that existing studies focus on qualitative approach in qualifying the phenomenon of interest through perceptions and values, and capturing the complexity of the event. Furthermore, no attempts were made to quantify the organizational pressure towards EA adoption. EA adoption studies were mainly undertaken in developed countries such as the USA, Finland and Belgium compared to developing countries. 
Therefore, this study suggests that the broad contexts within the organization should take into consideration for future works. Although the findings from previous studies have been tested with a qualitative approach, there is a deficiency of quantitative research methods employed in testing the factors that influence EA adoption. This may also assist researchers in explaining the relationship between factors or describing the trends of research problem with regards to EA adoption. Realising the discussions within the SLR undertaken by this researcher, future EA programmes must take into account the organizational pressures such as politics of government as it can provide comprehensive and rational views of business, information, and technology.

\section{ACKNOWLEDGMENTS}

The research is financially supported by the Public Service Department of Malaysia and iRMC, UNITEN under UNIIG 2017 Grant (Project Code: J510050737).

\section{REFERENCES}

[1] J. A. Zachman, "Enterprise Architecture: The Issue of the Century," Database Programming and Design, vol. 10, no. 3, pp. 44-53, 1997.

[2] M. Bernaert, G. Poels, M. Snoeck, and M. De Backer, "CHOOSE: Towards A Metamodel for Enterprise Architecture in Small and Medium-Sized Enterprises," Information Systems Frontiers, vol. 18, no. 4, pp. 781-818, 2015.

[3] G. P. Maxime Bernaert, Monique Snoeck,Manu De Backer, "Enterprise Architecture for Small and Medium Sized Enterprises: A Starting Point for Bringing EA to SMEs, Based on Adoption Models," 2014.

[4] P. Sousa, A. Caetano, A. Vasconcelos, C. Pereira, and J. Tribolet, "Enterprise Architecture Modeling with the Unified Modeling Language," in Enterprise Modeling and Computing with UML: IGI Global, 2007, pp. 67-94.

[5] S. Gilliland, P. Kotze, and A. van der Merwe, "Work Level Related Human Factors for Enterprise Architecture as Organisational Strategy," presented at the 2015 International Conference on Enterprise Systems (ES), 2015.

[6] F. Behrouz and M. Fathollah, "A Systematic Approach to Enterprise Architecture Using Axiomatic Design," Procedia CIRP, vol. 53, pp. 158-165, 2016.

[7] N. Syynimaa, "The Quest for Underpinning Theory of Enterprise Architecture: General Systems Theory," in ICEIS 2017: Proceedings of the 19th International Conference on Enterprise Information Systems. Volume 3, ISBN 978989-758-249-3, 2017: SCITEPRESS.

[8] J. J. K. Kari Hiekkanen, Jari Collin, Elisabete Patricio, Mika Helenius,Juha Mykkänen, "Architects' Perceptions on EA use : An empirical Study," 2013 IEEE International Conference on Business Informatics, 2013.

[9] J. J. Korhonen and M. Halen, "Enterprise Architecture for Digital Transformation," presented at the 2017 IEEE 19th Conference on Business Informatics (CBI), 2017.

[10] T. Iyamu, "Implementation of the Enterprise Architecture Through the Zachman Framework," Journal of Systems and Information Technology, vol. 20, no. 1, pp. 2-18, 2018.

[11] N. Syynimaa, "Method and Practical Guidelines for Overcoming Enterprise Architecture Adoption Challenges," in Enterprise Information Systems(Lecture Notes in Business Information Processing, 2017, pp. 488-514.

[12] C. Economics, "Enterprise Architecture Not Widely Embraced. February 2017," February, 2017 2017, Available: https://www.computereconomics.com/article.cfm?id=2330, Accessed on: March 26, 2018

[13] C. Economics, "Enterprise Architecture Adoption and Best Practices. April 2014," 2014.

[14] D. D. Dang and S. Pekkola, "Root Causes of Enterprise Architecture Problems in the Public Sector," in PACIS, 2016, p. 287.

[15] R. Depietro, E. Wiarda, and M. Fleischer, "The Context for Change: Organization, Technology and Environment," The Processes Of Technological Innovation, vol. 199, no. 0, pp. 151-175, 1990.

[16] K. Hjort-Madsen, "Architecting Government: Understanding Enterprise Architecture Adoption in the Public Sector," IT-Universitetet i København, 2009.

[17] K. Hjort-Madsen, "Institutional Patterns of Enterprise Architecture Adoption in Government," Transforming Government: People, Process and Policy, vol. 1, no. 4, pp. 333-349, 2007.

[18] F. D. Davis, "Perceived Usefulness, Perceived Ease of use, and User Acceptance of Information Technology," MIS quarterly, pp. 319-340, 1989.

[19] P. DiMaggio and W. W. Powell, "The Iron Cage Revisited: Collective Rationality and Institutional Isomorphism in Organizational Fields," American Sociological Review, vol. 48, no. 2, pp. 147-160, 1983.

[20] R. B. Duncan, "The Ambidextrous Organization: Designing Dual Structures for Innovation," The Management Of Organization, vol. 1, pp. 167-188, 1976.

[21] J. Hage and M. Aiken, "Social Change in Complex Organizations". Random House Trade, 1970.

[22] B. Wejnert, "Integrating Models of Diffusion of Innovations: A Conceptual Framework," Annual Review of Sociology, vol. 28, 2002.

[23] S. A. Simon Weiss, Robert Winter, "Institutionalization and the Effectiveness of Enterprise Architecture Management," Governance and Management of IS, 2013. 
[24] B. D. Rouhani, M. N. r. Mahrin, F. Nikpay, R. B. Ahmad, and P. Nikfard, "A Systematic Literature Review on Enterprise Architecture Implementation Methodologies," Information and Software Technology, vol. 62, pp. 1-20, 2015.

[25] D. Dang and S. Pekkola, "Enterprise Architecture and Organizational Reform: A Project Debrief," in Proceedings of the 21st Pacific Asian Conference on Information Systems 2017 (PACIS'2017), 2017.

[26] D. D. Dang and S. Pekkola, "Problems of Enterprise Architecture Adoption in the Public Sector: Root Causes and Some Solutions," in Information Technology Governance in Public Organizations(Integrated Series in Information Systems, 2017, pp. 177-198.

[27] N. Syynimaa, "Enterprise Architecture Adoption Method for Higher Education Institutions," University of Reading, 2015.

[28] K. Hjort-Madsen, "Enterprise Architecture Implementation and Management: A Case Study on Interoperability," Proceedings of the 39th Hawaii International Conference on System Sciences - 2006, 2006.

[29] V. Seppänen, "From Problems to Critical Success Factors of Enterprise Architecture Adoption," Jyväskylä studies in computing; 1456-5390; 201., 2014.

[30] N. A. Abu Bakar, S. Harihodin, and N. Kama, "Service-Oriented Enterprise Architecture (SoEA) Adoption and Maturity Measurement Model: A Systematic Literature Review," International Journal of Computer, Information Science and Engineering, vol. 7, pp. 15-27, 2013.

[31] I. Shaanika and T. Iyamu, "Deployment of Enterprise Architecture in the Namibian Government: the Use of Activity Theory to Examine the Influencing Factors," The Electronic Journal of Information Systems in Developing Countries, vol. 71, no. 1, pp. 1-21, 2015.

[32] J. Lemmetti and S. Pekkola, "Understanding Enterprise Architecture: Perceptions by the Finnish Public Sector," in International Conference on Electronic Government, 2012, pp. 162-173: Springer.

[33] D. H. Olsen and K. Trelsgård, "Enterprise Architecture Adoption Challenges: An exploratory Case Study of the Norwegian Higher Education Sector," Procedia Computer Science, vol. 100, pp. 804-811, 2016.

[34] W. A. Cram, M. K. Brohman, and R. B. Gallupe, "Addressing the Control Challenges of the Enterprise Architecture Process," Journal of Information Systems, vol. 29, no. 2, pp. 161-182, 2015.

[35] F. Damanpour and M. Schneider, "Phases of the Adoption of Innovation in Organizations: Effects of Environment, Organization and Top Managers," British journal of Management, vol. 17, no. 3, pp. 215-236, 2006.

[36] K. Barbara and C. Stuart, "Guideline for Performing Systematic Literature Reviews in Software Engineering (Version 2.3.)," Staffordshire, UK: University of Keele, 2007.

[37] P. S. Dang Duong, "Institutionalising Enterprise Architecture in The Public Sector in Vietnam," Association for Information Systems AIS Electronic Library (AISeL), no. Summer 6-15-2016, 2016.

[38] F. Nikpay, R. Ahmad, and C. Yin Kia, "A Hybrid Method for Evaluating Enterprise Architecture Implementation," Eval Program Plann, vol. 60, pp. 1-16, Feb 2017.

[39] H. S. Nur Azaliah A. Bakar, "Investigating Enterprise Architecture Implementation In Public Sector Organisation A Case Study Of Ministry Of Health Malaysia," presented at the 2016 3rd International Conference On Computer And Information Sciences (ICCOINS), 2016.

[40] K. S. Dilla Anindita Purnawan, "Building Enterprise Architecture for Hospital Information System," Fourth International Conference on Information and Communication Technologies (ICoICT), 2016.

[41] K. J. Klein, A. B. Conn, and J. S. Sorra, "Implementing Computerized Technology: An Organizational Analysis," Journal of Applied Psychology, vol. 86, no. 5, p. 811, 2001.

[42] R. Padilla-Pérez and Y. Gaudin, "Science, Technology and Innovation Policies in Small and Developing Economies: the Case of Central America," Research Policy, vol. 43, no. 4, pp. 749-759, 2014.

[43] E. MacLennan and J.-P. Van Belle, "Factors Affecting the Organizational Adoption of Service-Oriented Architecture (SOA)," Information Systems and e-Business Management, vol. 12, no. 1, pp. 71-100, 2013.

[44] B. T. Hazen, L. Kung, C. G. Cegielski, and L. Allison Jones-Farmer, "Performance Expectancy and Use of Enterprise Architecture: Training As An Intervention," Journal of Enterprise Information Management, vol. 27, no. 2, pp. 180-196, 2014.

[45] S. S. Hussein, M. N. r. Mahrin, and N. Maarop, "Preliminary Study of Malaysian Public Sector (MPS) Transformation Readiness through Enterprise Architecture (EA) Establishment," 2017.

[46] A. Alwadain, E. Fielt, A. Korthaus, and M. Rosemann, "Empirical Insights into the Development of A ServiceOriented Enterprise Architecture," Data \& Knowledge Engineering, vol. 105, pp. 39-52, 2016.

\section{BIOGRAPHIES OF AUTHORS}

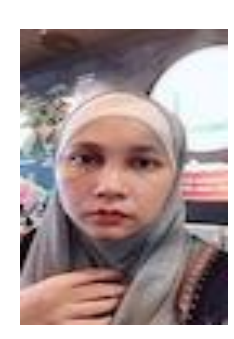

Nor Azizah Ahmad received her Dip. Comp Sc., B.Com. Sc. (Network Management) from Universiti Putra Malaysia (UPM) and Master in Electronic Bussiness Management from International University of Japan (IUJ) in 1999, 2002 and 2009 repectively. He is currently pursuing a Ph.D. degree (ICT) at the Department of Information System, College of Computer Science and Information Technology Universiti Tenaga Nasional (UNITEN) Putrajaya, Malaysia. Her research interests include Enterprise Architecture adoption, Electronic Bussiness Management and Network Management. 


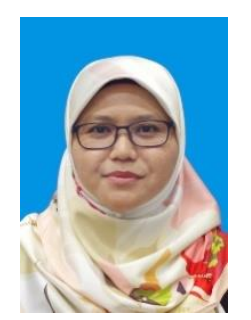

Sulfeeza Mohd Drus is a Senior Lecturer Universiti Tenaga Nasional (UNITEN). She is currently holding the post of Head of Informatics Department, College of Computing and Informatics at Universiti Tenaga Nasional. She obtained her first bachelor's degree in Management Information System from Clarkson University, US in 1998. She then pursued her postgraduate studies in Universiti Tenaga Nasional and obtained her Master's degree and PhD in 2007 and 2014 respectively. She is Dell EMC Certified Data Science Associate and her research interests include, but not limited to Knowledge Management, Knowledge Audit, and Data Science. She can be contacted via email address sulfeeza@uniten.edu.my.

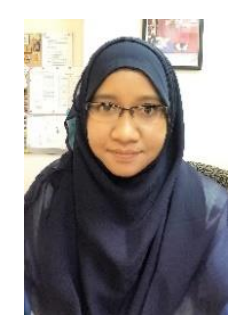

Nur Azaliah Abu Bakar is Senior Lecturer at Razak Faculty of Technology and Informatics, Universiti Teknologi Malaysia (UTM AIS). She graduated with a Bachelor (Information Technology) in Information Systems Engineering from Multimedia University (MMU) Malaysia (2000). She then obtained her Master's in Information Technology from Universiti Teknologi Mara (UiTM) in 2004. In 2017 she was awarded a Doctor of Philosophy degree in Information Technology (Enterprise Architecture) by Universiti Teknologi Malaysia (UTM). She has 20 years experience in ICT and has served in the Public Sector as well as several multinational companies. Her topics of expertise and research interests include, but are not limited to Informatics, Enterprise Architecture, Data Analytics, Business Intelligence and ICT Strategic Planning. She can be contacted via email address azaliah@utm.my 